\title{
Intensive home support for mental health crises: experience of the Trieste territorial crises team, in Italy
}

\section{Suporte domiciliar intensivo para crises em saúde mental: experiência da equipe de crise territorial de Trieste - Itália}

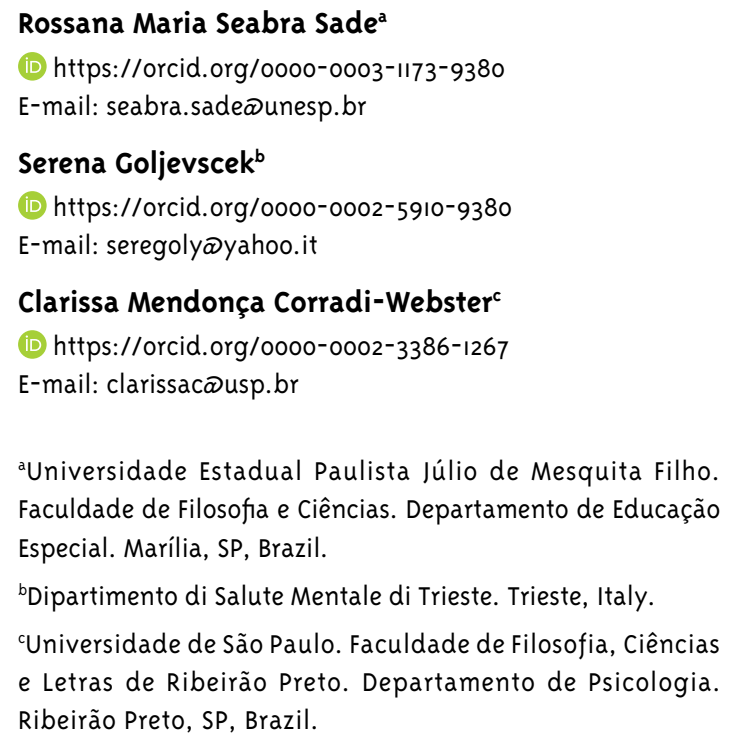

anniversidade Estadual Paulista Júlio de Mesquita Filho. Faculdade de Filosofia e Ciências. Departamento de Educação Especial. Marília, SP, Brazil.

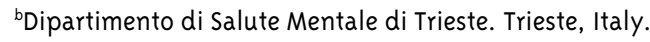

'Universidade de São Paulo. Faculdade de Filosofia, Ciências e Letras de Ribeirão Preto. Departamento de Psicologia. Ribeirão Preto, SP, Brazil.

\section{Abstract}

Early management of mental health crises is important for a good prognosis and treatment adherence. Ideas have been proposed to address crisis situations at home, aiming to reduce hospitalizations and medication doses and to increase care satisfaction. Identifying experiences of home care for mental health crises can support managers and professionals in proposing innovative practices. This article aims to describe the experience of Trieste, in Italy, which implemented a home crisis team service. The work is carried out in four phases: application of the inclusion criteria for treatment by the crisis team; initial assessment; co-construction of the therapeutic plan; discharge and transition to other services. In one year, the team performed 124 assessments and provided care for 59 people. Regarding psychiatric symptoms, 93\% of the patients showed significant improvement at discharge. Considering overall functioning, $81 \%$ showed significant improvement. Data show a reduction of compulsory admission rates of $29.4 \%$ in the first semester of 2018 and of $78.8 \%$ in the second semester, compared to 2017. The home crisis team achieved its goals of holistically caring for suffering individuals and reducing their contact with hospitals.

Keywords: Mental Health; Crisis; Home Care.

\section{Correspondence}

Rossana Maria Seabra Sade

Av. Rio Branco, 1233. Marília, SP, Brazil. Zip Code 17500-002. 


\section{Resumo}

O manejo precoce da crise em saúde mental é importante para bom prognóstico e adesão ao tratamento. São propostas experiências para atender situações de crise em domicílio, com objetivo de diminuir internações, doses de medicamentos e aumentar satisfação com o atendimento. Conhecer experiências de cuidado domiciliar em crises em saúde mental pode auxiliar gestores e profissionais na proposição de práticas inovadoras. O objetivo deste artigo é descrever a experiência de Trieste, na Itália, que implementou o serviço de equipe de crise domiciliar. 0 trabalho é realizado em quatro fases: aplicação dos critérios de inclusão no tratamento da equipe de crise; avaliação inicial; co-construção do plano terapêutico; alta e transição para outros serviços. Em um ano a equipe fez 124 avaliações e admitiu 59 pessoas. Em relação aos sintomas psiquiátricos, observou-se, no momento de alta, melhora significativa em $93 \%$ das pessoas. Quanto ao funcionamento global, houve melhora significativa em $81 \%$. Os dados apontam uma redução de internações compulsórias de 29,4\% no primeiro semestre de 2018 e de $78,8 \%$ no segundo, comparado a 2017. A equipe de crise em domicílio cumpre seus objetivos de cuidar do indivíduo em sofrimento de modo holístico, diminuindo o contato com hospitais.

Palavras-chave: Saúde Mental; Crise; Atendimento Domiciliar.
The history of madness is tied to how modern Western society constructs its thinking, social organization, production of knowledge, and exercise of power. For Foucault (2004), the concept of madness and crisis are historically and socially constructed according to the contextual social contingency in which the individual is included, showing that, over the centuries, what is now known as psychotic crisis has been called demonic possession, witchcraft, wisdom, subversion and, since the 18 th century, illness. For each definition, a different form of intervention was implemented: death by fire, exorcism, moral treatment, imprisonment, electroshock therapy, lobotomy, and physical and chemical restraint, among others. All these repressive and violent approaches aimed at placating the crisis and returning the person to the standard of normality imposed by society.

Over recent decades, the international psychiatric reform has provided a variety of mechanisms for the mental health care model which prioritize social inclusion, effective citizenship and autonomy of people with mental illness. However, this transformation process has faced obstacles in the effort to overcome the biomedical and hospital-centered mental health model. In this context, the protagonism of the social movement of patients, their relatives and the mental healthcare providers has favored changes in both legislation and the proposition of new models and approaches to the care, constituting a pillar of the deinstitutionalization process.

For Rotelli (2014), deinstitutionalization is not based on healing, but on emancipation, on creating models and opportunities, demystifying madness. Knowledge that has sustained the foundations of psychiatry since the Enlightenment-the notion of madness as alienation, as wrong, as dangerousmust be deconstructed and replaced by the notion of difference, of the production of life and of subjectivity. Any search for transforming the psychiatric paradigm should not be limited to abolishing asylum structures, but also include constructing new possibilities in which the actors involved actively participate in all processes of change, deconstructing the concept of normality associated with the established social standard, 
which defines the parameter between normal and madness.

When Basaglia (1985) mentioned the importance of putting illness in brackets, challenging psychiatry as the holder of power in mental health, he proposed a new dynamic for the relation between the mental health team and the social actors, looking for an axis on the fine line of the so-called "normalcy." To achieve a balance between these relations we must overcome the barriers of what is called the deviation from the norm. The deviation is added to the crisis, a concept that psychiatry has historically associated with the established social standard of what is "normal" (Mezzina, 2014).

According to Dell'Acqua and Mezzina (1991), there is no single definition of crisis in psychiatry, with several aspects being considered, including the psychiatric organization of the place, the historical moment and emotional problems. The development of the concept of "crisis" has been historically associated with the socially established standard of what is "normal." The word crisis derives from the Greek word krisis, meaning to separate, to distinguish, to make judgment. In Latin, crisis means a decision, a turning point, a rupture. As a word with such broad meaning, mostly pointing towards change and transformation, it seems unfair for it to hold the negative status imputed by psychiatry.

Caplan (1980), using the word as a psychiatric term, defines crisis as a rupture in the person's state of balance that arises when the individual encounters an obstacle to an important life goal, which seems to be insurmountable using the usual problem-solving skills (Rosen, 1997). Crises are transition periods in a person's life, which affect the family and social context and often represent a turning point: they may be seen as challenges or threats, gains or losses. Mostly, people pass through crises without any professional intervention, considering them to be normally expected life experiences. Nevertheless, there are crises in life which exceed the coping resources and may require help to overcome.

The crisis is the prime place to construct connections and work through the therapeutic process. It is one of the major phenomena in mental health, due to being laden with the social model of normalcy, which provokes great suffering in the individual going through the crisis and those that share it. Dell'Acqua and Mezzina (1991) advocate that a crisis develops in the collective space, and that the social actor must be able to go through it without losing their connection with the environment and/or the meaningful people in their life, thus allowing to enlarge possibilities and new bonds with the mental health service.

According to Saraceno (2001), even in a moment of crisis, the person is not limited to itself. The various forms and moments of the individual who suffers must be seen, inside and outside the crisis, always considering their socio-culturalhistorical and family context. Therefore, every transformation in psychiatric models must be ruled by the creation of new possibilities, in which social actors undergoing mental suffering actively participate in the processes of change, as the creators of their own lives. This analysis highlights the need to seek a new model of crisis approach, organized by systematic actions, considering the viability of home care, with the individual stripped of the sick role and the view of the redeemed person's existence and suffering, via a new perception no longer focused on the illness-cure duality.

To respond to mental health crisis situations with extra-hospital resources, crisis intervention teams have been constituted in several countries. For Wheeler et al. (2015), they constitute a new praxis of care during crisis and an alternative to hospitalization, in which people are treated at home-a less restrictive environment that allows for the minimum interruption of their lives.

Crisis Resolution Home Treatment (CRHT), according to Morant et al. (2017), acts in mental health by enabling rapid assessment and intensive home care for individuals experiencing a crisis. This intensive home care provided by crisis teams to people undergoing psychological suffering has diminished the need for hospitalization in psychiatric services. The aim of this process is to maintain the singularity of the person's daily life in their relational context, broadening perspectives by manifesting needs, dignity and rights, considering 
the person's normalcy, as someone undergoing suffering, without the need for categorizing between chronic and acute crisis.

Crisis resolution and home treatment teams have been widely introduced in the mental healthcare system throughout the world. This model has evolved as a practical response to difficulties in the acute mental health care system, continuously adapting and developing over the years. These teams are designed to assess people being considered for acute hospital admission, to offer intensive home treatment rather than hospital admission, when possible, and to facilitate early discharge.

In the 1980s, in Finland, a group coordinated by the psychologist Jaakko Seikkula developed Open Dialogue, a systemic intervention method aimed at working with people suffering psychological distress and experiencing crisis. In it, treatment begins within the first 24 hours from the first contact between the health system and the person, their family or social network. The psychotherapeutic treatment of Open Dialogue involves the entire support network connected to the individual in crisis and is performed by professionals working as mobile crisis intervention teams (Seikkula; Laitila; Rober, 2012). This system was implemented in all health and social service networks in Western Lapland. The philosophy of Open Dialogue focuses on the relationships between the person in crisis, their family and the social network.

Another experience of crisis intervention in catchment areas was carried out in the United Kingdom (Department of Health, 20oo). There are some principles on which most professionals involved in the development of the crisis team model seem to agree: (1) a critical view on hospital admission, regarding its long-term therapeutic effects and the user's intense feeling of stigma connected to it; (2) home treatment allows better assessment and addresses the social and environmental triggers of crisis; and (3) less inequalities of powers regarding the relationship between patients and professionals when crises are managed in people's own homes (Wheeler et al., 2015).

The core model of the crisis team includes a set of organizational characteristics and interventions, which involve multidisciplinary teams, trained to provide a full range of acute psychiatric interventions to the community. These include a rapid assessment offered in the community; the opportunity for intensive home treatment rather than hospital admission; when admission is necessary, the team works to guarantee an early discharge; 24 hour service; the team working in partnership with community services; a gate-keeping role, meaning that the teams control access to local acute inpatient beds; and intensive shot-term home treatment, less than 6 weeks (Johnson, 2013).

A literature review found that CRHT provides potential benefits by reducing the high costs and negative experiences users have with hospitalizations (Wheeler et al., 2015). And that to work well, these treatments require communication and integration with other mental health services and providing homecare with little variability of visiting team members. The quantitative studies included in the review suggest that the presence of a psychiatrist on the team and functioning outside business hours increased the potential of CRHT to prevent hospitalizations.

On average, $20 \%$ of the people attended by the crisis teams are hospitalized (Cotton et al., 2007). A study conducted in Norway with patients treated by CRHT found that the chances of being hospitalized were higher among those with psychotic symptoms, suicide risk and previous history of hospitalizations (Hasselberg et al., 2013). In England, a study observed that the major predictors for hospitalization after CRHT attendance were: having been uncooperative in the initial assessment; having a risk of self-neglect; having a history of involuntary hospitalizations; and having been evaluated outside business hours or in hospital clinics (Cotton et al., 2007). Brimblecombe, O'Sullivan and Parkinson (2003) also highlighted previous hospitalizations, suicide risk and having been referred by other professionals, such as the police and legal system, as predictors.

Early management of the mental health crisis is key for a good prognosis and user's adherence to treatment. The possibility of home care has been presented as an option for this management, reducing hospitalizations and prescribed medication doses and increasing satisfaction with the care provided for the user. Considering this, the Department of Mental 
Health in Trieste - Italy, Collaborating Center of the World Health Organization for Mental Health Care, has been implementing crisis resolution teams since 2017. This article aims to describe this municipality's experience with implementing the home crisis team service, which provides care for people with psychological distress in crisis. With this report, we hope to encourage managers and providers to evaluate implementing mental health crisis teams.

\section{Crisis Teams: the experience in Trieste}

The experience of the Crisis Resolution Home Treatment team reported here is part of a larger process of mental health service reorganization, coordinated by the Mental Health Department (MHD) of Trieste. These services have been historically constructed to operate based on the territory and community. The Mental Health Department integrates the public health service and coordinates all psychiatric requirements in its territory. Its main structures, that work in a complementary way, are: Mental Health Centers (MHCs); Psychiatric Service for Diagnose and Care (PSDC); and Residential, Semi Residential and Rehabilitation Facilities.

Mental Health Centers are residential structures located within the community, with 24-hour open access, seven days per week. They offer outpatient activities and can be considered places of meeting and exchange, in addition to providing specialized healthcare interventions and programs, for both users and their families. They also offer six beds for overnight stays. Their mission is to provide continuity of therapeutic-rehabilitative interventions, especially for people suffering from severe mental disorders, including constant support for accessing social opportunities (housing, education, health management, and leisure time activities), accompanying them in personalized rehabilitative pathways and referring them to other services and institutions, when needed. Trieste has four Mental Health Centers, each comprising a multidisciplinary team and covering an area including 60,ooo inhabitants.

The Psychiatric Service for Diagnosis and Care (PSDC) is a 24 hours service, open seven days a week, and works in close contact with the emergency service and with Triste's other mental health services, such as the mental health centers. This service is based in the general hospital, attending to the different emergency situations that arise at the hospital. The service's doors are always open, and a non-restraint policy has been adopted for the last 40 years. It has six beds for short-term admissions, aiming to rapidly connect with the local community service so they take charge of the person. There are two psychiatrists and 18 nurses, who alternate over three shifts (morning-afternoonnight). The Psychiatric Service for Diagnosis and Care aims to reduce hospitalization time as much as possible, always promoting the role of the Mental Health Center as the place for recovery, following the principle of community care. This model has enabled patients to maintain contact with their community, even in the most serious situations, confirming the possibility of avoiding institutionalization. Overall, the PSDC is an important link between hospital and community.

Despite the limited number of hospitalizations, the Department of Mental Health of Triste still felt the need to provide early attention to crisis situations, seeking to enhance other trajectories for those who needed it, improving the partnership between mental health and care services and reducing the number of hospitalization days. Thus, the municipality decided to form a mobile crisis team, which could support people in crisis situations in the territories, without having to refer them to the mental health center or the hospital service. Accordingly, in October 2017, the Azienda Sanitaria Universitaria Integrata di Trieste formed the "Homecare Crisis Attention Team" (based on Crisis Resolution Home Treatment - CRHT).

The team acts as an alternative to hospitalization for people suffering acute psychiatric breakdown. The entire process works toward helping the individual to face the crisis, by developing coping mechanisms to regain control of their life as soon as possible and to avoid future crises. This service is located in the city center, at the general hospital and integrates the Psychiatric Service for Diagnosis and Care. The team comprises 12 professionals: two psychiatrists, a general practitioner, a social worker, an occupational therapist, six nurses and 
a medical student. In the morning, between two and five professionals are available in the team, in the afternoon two and at weekends one or two professionals. Besides the specific tasks of the profession, all professionals have the flexibility to act on the different needs that the situations require. The service opens Monday to Friday, from $8 \mathrm{AM}$ to $8 \mathrm{PM}$ and on weekends and holidays, from $9 \mathrm{AM}$ to $5 \mathrm{PM}$. It is equipped with two cars and two cell phones, whose numbers are provided to users in care and to the various mental health or chemical dependency services. The team attends between 4 and 10 people per day.

The work of the Crisis Team will be described in four phases: (1) criteria for participating in the crisis team treatment; (2) initial assessment; (3) co-construction of the therapeutic plan; and (4) discharge and transition to other services.

\section{$I^{\text {st }}$ Phase: criteria for participating in the Crisis Team Treatment}

Referrals are made by the PSDC, Mental Health Centers and emergency agencies, as they perform the first clinical assessment. These services forward a report to the crisis team with the person's characteristics and their clinical condition. One of the crisis team professionals-usually the psychiatrist-will evaluate the case, considering the inclusion and exclusion criteria. As inclusion criteria for starting home-treatment, they consider: acute psychiatric symptomatology, with recent deterioration; crisis in relationships/severe isolation; and requests for help for problematic distressful situations related to family/work environment/neighborhood/emergency agencies. The exclusion criteria considered include: severe risk of self-harm; acute substance intoxication/ severe drug abuse/addiction that at first requires medical intervention; dementia/delirium, which needs specific and intensive day care by trained staff; user's or family's refusal; not classified as an ongoing crisis; and the need for compulsory treatment (no other possible option).

This first phase is completed in up to two days. If this first evaluation indicates that the patient can benefit from their type of service, the team starts the second phase.

\section{$2^{\text {nd }}$ Phase: assessment}

Clinical interviews are carried out and the reports are recorded in a personal file. Usually performed by the crises team's nurses at the beginning of the first meeting, these interviews aim to gather information regarding the individual's personal and family history, previous experiences of psychiatric or psychological suffering (as well as the overall health condition), and a more detailed analysis and description concerning the existing psychiatric problem. Past trauma and suicide risk are given great importance in the first clinical evaluation; the final part of the report addresses possible therapeutic interventions. This first step is, whenever possible, carried out together with the user's mental health referral center.

To complete the assessment, the team administers two specific tests, which investigate the major symptoms expressed by the patient and their overall functioning: the Brief Psychiatric Rating Scale (BPRS) and the Global Assessment of Functioning (GAF). The first is a rating scale used to measure psychiatric symptoms such as depression, anxiety, hallucinations and unusual behavior; a total of 24 symptoms are scored and rated 1 to 7 (Overall; Hollister; Pichot, 1967). The Global Assessment of Functioning (GAF) is a numeric scale used by mental health physicians to subjectively rate the social, occupational and psychological functioning of an individual; scores range from 100 (extremely high functioning) to 1 (severely impaired) (Piersma; Boes, 1997).

The same tests are carried out at discharge, with the addition of three others: the Clinical Global Impressions Scale (CGI), Scale to Assess the Therapeutic Relationship for Patients (STAR-P) and the Client Satisfaction Questionnaire (CSQ-8). CGI measures the severity of the symptoms, the patient's level of distress and other aspects of impairment, the impact of the illness on functioning and the efficacy of treatments in patients with mental disorders (Busner; Targum, 2007). STAR-P evaluates the therapeutic relationships between 
clinician and patient from the patient's point of view, as the quality of this relationship has been found to predict treatment adherence and outcomes across a range of patient diagnoses and treatment settings (Mcguire-Sniekus et al., 2007). CSQ-8 is a scale designed to assess patient's satisfaction with health and mental health services (Attkisson; Zwick, 1982). The BPRS, GAF and CGI are also administered 3 and 6 months after discharge to evaluate the efficacy over time of the therapeutic intervention and the person's psychophysical condition in post-crisis.

\section{$3^{\text {rd }}$ Phase: co-construction of the therapeutic plan}

An essential part of crisis management is developing a shared therapeutic plan, done at the start of the care: a brief document is developed to share a therapeutic project among the user, family and the Mental Health Center professionals. This document highlights the user's fragilities and vulnerabilities and their resources and needs. Short-term goals are agreed upon together, with regular meetings held with the user, family and group of care providers, to check the therapeutic plan. The whole group participates in developing the home-treatment interventions, concerning intensity, duration and frequency.

The home-treatment interventions include different actions, such as: support for everyday life; individual and family structured psychological support (families, if available, are immediately involved in the user's care trajectory); support/ monitoring of physical health; support for pharmacological compliance and monitoring of medication intake; articulation of support/ collaboration networks with institutions/ community; and participation in social activities.

The team provides evaluation, support and multidisciplinary treatment 12 hours a day, five days a week. The care is intensive, with home visits occurring up to twice a day, with a gradual reduction in frequency according to clinical improvement. The visits are always carried out by two professionals in rotation, so the patient can be in contact with the same professionals with the same approach. At the beginning of the treatment, frequency, intensity and type of intervention are flexibly agreed upon between the team and the user, considering the user's needs. For example, they decide together whether visits are to occur at the user's home or elsewhere in the region. This allows to immediately approach the user's family and life context, enabling a broader view of the person's needs and weaknesses, ensuring more effective and targeted support. Constructing the therapeutic project takes place by cooperation between the team, the user and their family, as well as other individuals chosen by the patient. The average length of the intervention process is approximately four weeks.

The team organizes its routine as follows: early in the morning there is a brief meeting to assess new cases that occurred during the night. Afterwards, the team discusses the cases already being monitored, seeking to reassess them and organize the day's visits. Two professionals are responsible for the morning visits. Another meeting follows in the early afternoon, to report on the morning visits and schedule the afternoon activities. These meetings are a fundamental and necessary tool for the development of teamwork, promoting the integration of work.

\section{$4^{\text {th }}$ Phase: discharge and transition to other services}

The team works integrated with the local mental health center: around the fourth week on average, the center takes over the care, continuing with the therapeutic approach collectively defined. Due to the restricted number of patients the team can attend and the wide range of people being cared for by the centers, this articulation between the crisis team and the Mental Health Centers remains a challenge. At the time of writing this article, this articulation was still being accessed by the team.

Good relations and communication with other services (acute wards or mental health centers) are considered important aspects for effective crisis teamwork, with problems in the continuity of care and good inter-service communication often being reported by stakeholder groups. Working together at discharge helps to ensure the reliable continuity of the care: for example, informing General 
Practitioners or other mental health services about changes in the medication and ensuring physical health monitoring and interventions. Develop clear inter-service communication between the crisis teams and the acute and community mental healthcare systems is highly desirable, as it acts to optimize and enhance the long-term effects of the intensive home treatment and to create a system tailored to service users' needs (Morant et al., 2017).

Morant et al. (2017) emphasized the importance of the team's quick response time. Care must be offered consistently by the same team to increase opportunities for bonding and to facilitate integration with other partnering services. Frequent contact creates space for reliability and clarity, which is extremely important for the individuals receiving attention. According to one of the patients, what matters is the daily support, the certainty I woke up to every morning, that however scared or upset I was, someone would be coming to see me.

\section{Preliminary results}

The Trieste Crisis Team began its activities in October 2017, thus the data presented here refer to its first year run, i.e. until October 2018. During this period, the team performed 124 assessments and, using the inclusion and exclusion criteria, selected 59 people for monitoring by intensive homecare. As previously explained, the care provided was assessed through the BPRS and GAF instruments. Regarding the psychiatric symptoms evaluated by the BPRS, $93 \%$ of the people attended $(n=55)$ showed significant improvement at discharge. As for the overall functioning assessed using GAF, $81 \%$ of the people $(n=48)$ showed significant improvement.

Regarding admission rates and the characteristics of the Diagnosis and Psychiatric Care Service, the data show a reduction of $29.4 \%$ in compulsory admission rates for the first semester of 2018 and of $78.8 \%$ for the second semester, compared with 2017. Further data are constantly being collected to expand the sample available and to obtain long term outcomes for this intensive home support during acute psychiatric breakdowns.

\section{Example of care provided: Fabio's story}

Fabio, a 19-year-old adolescent, was referred to the Mental Health Center by his parents, who directly called the service, asking for an urgent psychiatric evaluation for their son. At the age of 17, Fabio started expressing psychopathological suffering characterized by phobic-obsessive thoughts, with compulsive-almost self-harming-behaviors, severe social withdrawal and insomnia. Fabio's phobicobsessive traits focused on the body, especially the hair, which he compulsively shaved, producing wounds: he routinely monitored his body, mapping every single part and pulling out whatever hair he encountered. He used to spend hours meticulously checking his skin for hair, to "clean" it; he told us that, during a holiday with his family, he was stuck in his room "getting ready" for about 12 hours, and spent all night standing to completely shave his body, face and head. This pathological condition affected Fabio's overall functioning, especially his social awareness and life-event coping skills, which had been impaired since the first signs of his suffering.

Fabio was introduced to the CRHT during a team meeting at his Mental Health Center and they decided to perform a home visit that same day to evaluate the overall clinical situation and to jointly develop a possible intervention trajectory. Fabio initially seemed puzzled and hesitant about daily home visits and asked the team to start with three home-visits per week. During the visits, which lasted up to two hours, Fabio slowly began to open up about his story. Family members (especially his mother) were often present at the meetings and actively participated in them. Fabio gradually began to create a more autonomous relationship with his mother, less affected by the feelings of guilt and inadequacy that had kept him in anguish and disallowed him to live freely. After the first 2 weeks, Fabio agreed to increase the frequency of the home-visits and the team started visiting him 5 days a week, from Monday to Friday.

Fabio's mental health slowly began to improve: he felt less anguished and was able to tolerate and manage his obsessive thoughts and to control his compulsions. Still in the first period of his acute psychiatric distress, Fabio received a low dose of 
psychopharmacological therapy, initially composed of Aripiprazole 1omg/day and Delorazepam 2mg/day. Although effective for the obsessive symptomatology and insomnia, the therapy produced a fair amount of sialorrhea that Fabio found intolerable. The team, thus, decided to replace Aripiprazole with oral Paliperidone $6 \mathrm{mg}$ /day, with good results in the symptoms and no significant adverse effects. The Delorazepam was gradually suspended as he recovered regular sleep.

After the 1 month mark, Fabio began to gradually go out, first in short walks with a member of the team and later independently, using public transport to reach his grandmother's house downtown. In time he started new activities: he enrolled on a video-making course and his family offered him the opportunity to spend some hours/day with a private educator, who continued to help him engage in outside activities and to restart school, which he had interrupted at 17.

During the discharge phase, the team agreed to develop a progressive therapeutic plan with the mental health center, scheduling regular meetings with the service's psychiatrist and maintaining a continuous relationship with the referring operators. They focused on specific rehabilitation activities, which were chosen and managed directly by Fabio. At discharge, he was doing well, studying to get his driver's license and preparing to enroll in school again.

\section{Final considerations}

The article aims to contribute to the discussion on the work and the routes of care in mental health crises, by presenting a service recently implemented in Trieste, Italy. The Trieste crisis attention team operates on a holistic view of the individuals: helping them in crisis management, being present in their relationships with family, and emotionally supporting them through it. A non-judgmental, non-stigmatizing approach is made possible by the team's interaction and work dynamics. The care requires the team share its power, considering the individuals and not their illnesses, respecting their subjectivity and creating perspectives where they can become the protagonists in reconstructing their own story.

According to Dell'Acqua (2014), the mental health professionals' role changed when they started to find new meanings for the complexity of the problem, without deeming madness a fault, disability, insanity or mental illness; by respecting the individual's way of living as a different kind of relationship with the world. Accordingly, knowledge should not be used as a normative technique, but as a possibility for creating new subjectivities. The technique ceases to be an instrument of violence when the exercise works to deconstruct practice. The Trieste crisis attention team enables a new perception of the suffering individual and gives new meaning to the Open Doors operation.

Open Doors means stop reproducing the asylum control, providing care in the everyday freedom of one's own home and admitting a new relationship with madness (Nicácio; Gastão, 2005). It requires transforming the team's relationship with power, demanding new ways of acting in peoples' everyday lives, by constant negotiations and by constructing a new practice. Creating a new set of strategies aims to respond, in an increasingly articulated way, to the complexities and diversities of needs, desires and projects of the social actors that emerge in this context of transformation. According to Rotelli (2014), the question concerns the willingness to make a serious mental health policy and to proceed step by step in this direction, tirelessly, continuing to put oneself in the relationship between exclusion and inclusion, making community mental health services stronger, considering that rights are weak anyway, and one needs to be strong to defend the rights of the weak.

We need approaches that prioritize human dignity and the empowerment of people with psychic suffering. Normally, the approach to mental crisis is linked to its definition, which is associated with the concept of “disease." The ideas of Basaglia (1985) and Dell'Acqua and Mezzina (1991) contradict the definition of crisis as a "disease," considering the devices that participate in its cultural production to be a social and subjective event. They take the psychopathological status from the crisis and reaffirm its complexity. Constructing a new place for the crisis requires an epistemological openness whilst constructing non-standardized and a priori defined knowledge. It is the task of every healthcare provider to be surprised by the people they see each 
day, offering interventions that are constructed by contact with the individual in crisis and their uniqueness (Martins, 2017).

Puras and Gooding (2019) argue for a rightsbased approach to health that prioritizes human dignity and the treatment choices made by the services' protagonists, but with an emphasis on coercive practices and the imposition of treatment. Social actors who, over the years, have been chronified by medications and treatments become reflections of their pathology. Thus, the need to implement actions that promote home support for the person in crisis is urgent. Crisis team services in Latin America are almost nonexistent and the approaches to home interventions are unsystematic, disallowing the person to regain their autonomy and manage their crisis. Therefore, any transformation of the psychiatric models must be based on constructing new forms of possibilities, in which the suffering person actively participates in all the processes of change as a constructing subject of their life, thus seeking a new praxis of care for social actors in crisis.

\section{References}

ATTKISSON, C. C.; ZWICK, R. The client satisfaction questionnaire. Psychometric properties and correlations with service utilization and psychotherapy outcome. Evaluation and Program Planning, Oxford, v. 5 , n. 3, p. 233-237, 1982.

BASAGLIA, F. A instituição negada: relato de um hospital psiquiátrico. Rio de Janeiro: Graal, 1985.

BRIMBLECOMBE, N.; O'SULLIVAN, G.;

PARKINSON, B. Home treatment as an alternative to inpatient admission: characteristics of those treated and factors predicting hospitalization. Journal of Psychiatric and Mental Health Nursing, Oxford, v. 10, n. 6, p. 683-687, 2003.

BUSNER, J.; TARGUM, S. D. The clinical global impressions scale: applying a research tool in clinical practice. Psychiatry, Edgmont, v. 4, n. 7, p. 28-37, 2007.

CAPLAN, G. (Org). Princípios de psiquiatria preventiva. Buenos Aires: Paidós, 1980
COTTON, M. A. et al. An investigation of factors associated with psychiatric hospital admission despite the presence of crisis resolution teams. BMC Psychiatry, Londres, v. 7, p. 52, 2007.

DELL'ACQUA, G. Desinstitucionalização triestina: contextualização da "loucura" ao longa da história. In: SADE, R. M. S. Portas abertas: do manicômio ao território. Entrevistas triestinas. São Paulo: Cultura Acadêmica, 2014. p. 55-74.

DELL'ACQUA, G; MEZZINA, R. Resposta à crise. In: DELGADO, J. (Org.). A loucura na sala de jantar. São Paulo: Resenha, 1991. p. 53-79.

DEPARTMENT OF HEALTH. The NHS Plan: a plan for investment. A plan for reform. Londres: HMSO, 2000.

FOUCAULT, M. História da loucura. São Paulo: Perspectiva, 2004.

HASSELBERG, N. et al. Psychiatric admissions from crisis resolution teams in Norway: a prospective multicentre study. BMC Psychiatry, Londres, v. 18, n. 13, p. 117, 2013.

JOHNSON, S. Crisis resolution and home treatment teams: an evolving model. Advances in Psychiatric Treatment, Cambridge, v. 19, n. 2, p. 115-123, 2013.

MARTINS, A. G. A noção de crise no campo da saúde mental: saberes e práticas em um centro de atenção psicossocial (CAPS). Mental, Barbacena, v. 11, n. 20, p. 226-242, 2017.

MCGUIRE-SNIEKUS, R. et al. A new scale to assess the therapeutic relationship in community mental health care: STAR. Psychological Medicine, Londres, v. 37, n. 1, p. 85-95, 2007.

MEZZINA, R. Community mental health care in Trieste and beyond. An "open door-no restraint" system of care for recovery and citizenship. The Journal of Nervous and Mental Disease, Hagerstown, v. 202, n. 6, p. 440-445, 2014.

MORANT, N. et al. Crisis resolution and home treatment: stakeholders' views on critical ingredients and implementation in England. $B M C$ Psychiatry, Londres, v. 17, n. 254, 2017. Disponível em: <https://bit.ly/2VCOlL9>. Acesso em: 3 mar. 2018. 
NICÁCIO, F.; CAMPOS, G. W. S. Instituições de "portas abertas": novas relações usuários-equipescontextos na atenção em saúde mental de base comunitária/territorial. Revista de Terapia Ocupacional da Universidade de São Paulo, São Paulo. v. 16, n. 1, p. 40-46, 2005.

OVERALL, J. E.; HOLLISTER, L. E.; PICHOT, P. Major psychiatric disorders: a four-dimensional model. Archive of General Psychiatry, Chicago, v. 16, n. 2, p. 146, 1967.

PIERSMA, H. L.; BOES, J. L. The GAF and psychiatric outcome: a descriptive report. Community Mental Health Journal, Nova York, v. 33, n. 1, p. 35-41, 1997.

ROSEN, A. Crisis management in the community. Medical Journal of Australia, Sydney, v. 167, n. 11, p. 1-15, 1997.
ROTELLI, F. Entrevista. In: SADE, R. M. S. Portas abertas: do manicômio ao território: entrevistas triestinas. Marília: Oficina Universitária, 2014. p. 37-53.

SARACENO, B. Libertando identidades: da reabilitação psicossocial à cidadania possível. 2 . ed. Rio de Janeiro: TeCorá, 2001.

SEIKKULA, J.; LAITILA, A.; ROBER, P. Making sense of multi-actor dialogues in family therapy and network meetings. Journal of Marital and Family Therapy, Washington, DC, v. 38, n. 4, p. 667-687, 2012.

WHEELER, C. et al. Implementation of the crisis resolution team model in adult mental health settings: a systematic review. BMC Psychiatry, Londres, v. 15, n. 74, 2015. Disponível em: <https://bit.ly/2Aj7ZnZ. Acesso em: 23 fev. 2018.

\section{Authors' contribution}

Sade conceived the experience report, Goljevscek carried out the fieldwork and Corradi-Webster contributed to the critical review. All authors contributed to the writing of the manuscript.

Received: $28 / 05 / 2020$

Approved: 12/06/2020 